\title{
Shear Assessment of Reinforced Concrete Slab Bridges
}

\author{
Eva O.L. LANTSOGHT \\ PhD Candidate \\ Delft University of \\ Technology \\ E.O.L.Lantsoght@tudelft.nl
}

\author{
Cor VAN DER VEEN \\ Associate Professor \\ Delft University of \\ Technology \\ C.vanderveen@tudelft.nl
}

\author{
Joost C. WALRAVEN \\ Full Professor \\ Delft University of \\ Technnology \\ J.C.Walraven@tudelft.nl
}

\author{
Ane DE BOER \\ Senior Advisor \\ Rijkswaterstaat \\ Utrecht \\ ane.de.boer@rws.nl
}

\section{Summary}

The capacity of reinforced concrete solid slab bridges in shear is assessed by comparing the design beam shear resistance to the design value of the applied shear force due to the permanent actions and live loads. Results from experiments on half-scale continuous slab bridges are used to develop a set of recommendations for the assessment of slab bridges in shear. A method is proposed allowing to take the transverse force redistribution in slabs under concentrated loads into account, as well as a horizontal load spreading method for the concentrated loads. For selected cases of existing straight solid slab bridges, a comparison is made between the results based on the shear capacity according to the Dutch Code NEN 6720 and from the combination of the Eurocode (EN 1992-11:2005) with the recommendations, showing an improved agreement.

Keywords: slab bridges; shear; assessment; live loads; effective width; case studies

\section{Introduction}

In the Netherlands, a large number of the existing reinforced concrete bridges in the road network are short span solid slab bridges. $60 \%$ of these existing bridges have been built before 1975 . Since then, the traffic loads and intensity have increased significantly, which is reflected by the heavier live load models in EN 1991-2:2003 [1]. On the other hand, the shear capacity as prescribed by the codes is more conservative in the recently implemented EN 1992-1-1:2005 [2] than in the previously used national code NEN 6720 [3]. As a result, several existing slab bridges are found not to satisfy the criteria when assessed for shear according to the current codes. However, when these structures are inspected, no signs of distress can be observed [4,5]. Results from testing a decommissioned slab bridge [6] indicate that slab bridges possess a higher strength than found by current rating procedures. As a result of these observations and conclusions, the Dutch Ministry of Infrastructure and the Environment initiated a project to improve the assessment practice for existing bridges under the increased live loads. In total, the shear capacity of 600 reinforced concrete solid slab bridges should be verified.

The large number of solid slab bridges that are identified as shear-critical requires a systematic approach. In a preliminary general assessment the database of slab bridges was screened in order to identify the particular bridges requiring a more detailed analysis. For this purpose, a fast, simple and conservative tool is required: the Quick Scan method. The first Quick Scan sheets are developed by the Dutch Ministry of Infrastructure and the Environment in the mid-2000s. The output of these spreadsheets is a "unity check" ("uc") value: the ratio between the design value of the applied shear force resulting from the loads (dead loads and live loads) and the shear resistance. The wheel loads should be placed in such a way that the maximum shear stress is found near the edge of the support [7]. 
The shear capacity as prescribed by the codes under consideration (NEN 6720 [3] and EN 1992-11:2005 [2]) is determined by a semi-empirical expression based on experiments on relatively small, heavily reinforced concrete beams mostly loaded in four-point bending [8]. However, when a slab is loaded under a concentrated load, transverse load redistribution can result in higher shear capacities. This mechanism is not taken into account in the codes. Recently [9] experiments have been carried out to quantify the increase in shear capacity in slabs as compared to beams. These experiments form the basis for new recommendations for the shear assessment of slab bridges.

\section{Loads for assessment}

\subsection{Live load model}

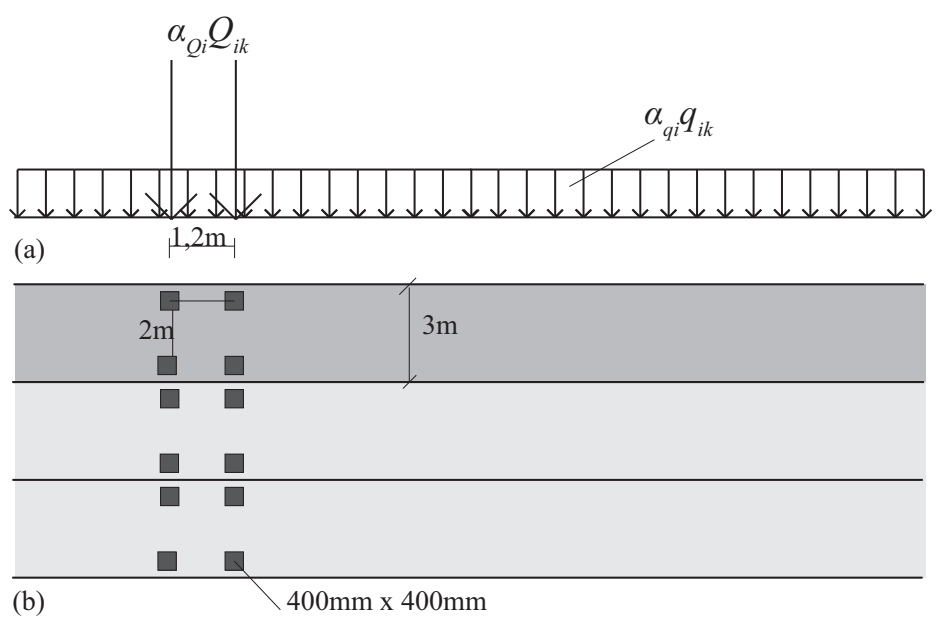

Fig. 1: Traffic loads according to EN1991-2:2003 [1] (a) side view; (b) top view.
The shear stress at the support results from the action of dead loads and live loads. The live loads are determined based on EN 1991-2:2003 [1] load model 1. According to this load model (Fig. 1), wheel loads are combined with a design lane load. The design truck has a tire contact area of $400 \mathrm{~mm}$ $\times 400 \mathrm{~mm}$ and an axle load of $\alpha_{Q 1} \times$ $300 \mathrm{kN}$ in the first lane, $\alpha_{Q 2} \times 200 \mathrm{kN}$ in the second lane and $\alpha_{Q 3} \times 100 \mathrm{kN}$ in the third lane. The values of $\alpha_{Q i}$ are given in the National Annex and are equal to 1 for the Netherlands. The lane load is applied over the full notional lane width (3m, Fig. 1) and equals $\alpha_{q i} \times$ $9 \mathrm{kN} / \mathrm{m}^{2}$ for the first lane and $\alpha_{q i} \times$ $2,5 \mathrm{kN} / \mathrm{m}^{2}$ for all other lanes. In the Dutch National Annex, for bridges with 3 or more notional lanes, the value of $\alpha_{q 1}$ equals $\alpha_{q 1}=1,15$ and for $i>1$ the value can be taken as $\alpha_{q i}=1,4$.

\subsection{Safety requirements and load factors}

Currently, the Eurocode suite can be applied for the design of structures, but guidelines for assessment of existing structures are not provided. For assessment according to the basic assumptions and philosophy of the Eurocodes, in the Netherlands a set of national codes (NEN 8700 [10] the basic rules, NEN 8701 [11] for actions etc.) is developed. Existing structures may be assessed for lower safety levels than newly designed structures. Therefore, different sets of load factors can be used. The two safety levels described in NEN 8700:2011 [10] are the repair level (used for assessment in the Quick Scans) and the replacement level. The load factors associated with the repair safety level are $\gamma_{D L}=1,15$ for dead loads and $\gamma_{L L}=1,3$ for live loads. The reliability index associated with these load factors is $\beta_{r e l}=3,6$ for structures built before 2012 [12] and for consequences class 3 from EN 1990:2002 [13].

\section{Recommendations}

\subsection{Effective width and lower bound}

Slab and slab strips with a width varying between $0,5 \mathrm{~m}$ and $2,5 \mathrm{~m}$ have been tested under 6 different loading conditions. The results are used to evaluate the horizontal load spreading methods. In line with the concept of the effective width (Fig. 2), for slab strips with a small width an increase of the specimen width should lead to an increase of the shear capacity: the full specimen width carries the load at the support. For larger widths, a threshold value should apply above which no further increase in shear capacity is observed with an increasing specimen width. This threshold value corresponds to the effective width which carries the load at the support, and is -according to the 


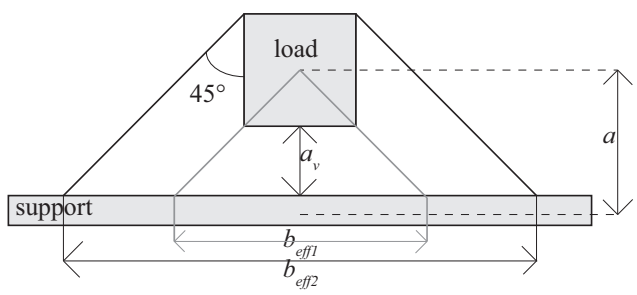

Fig. 2: Horizontal load spreading between concentrated load and support (top view of slab). Two approaches are shown: $b_{\text {effi }}$ results from load spreading from the centre of the load and $b_{\text {eff }}$ from the far side of the load. conservative results. However, the statistical analysis [14]
clearly indicates that the French load spreading method leading to $b_{\text {eff }}$ (Fig. 2 ) is to be preferred as it leads to a smaller underestimation of the capacity and a smaller coefficient of variation.
Slab S1T1, (S1T2) - effective width

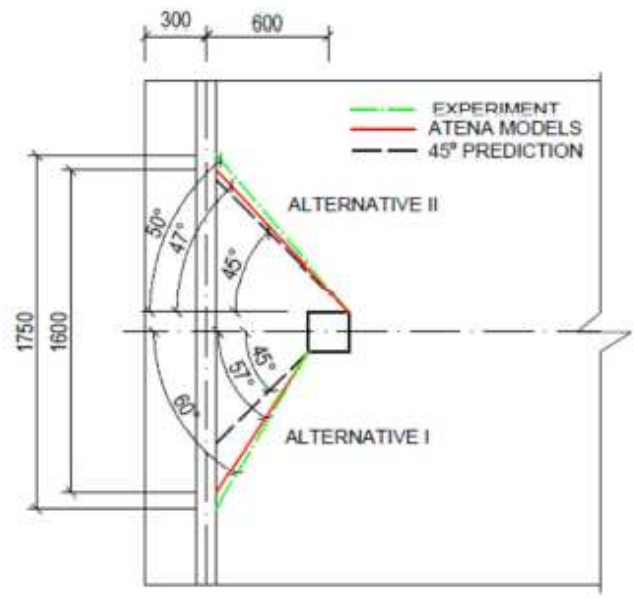

Fig. 3: The effective width based on nonlinear finite element calculations compared to the effective width resulting from the considered load spreading methods [16]. Legend: green = observed cracking at bottom of slab; red = based on stress distribution in NLFEA; black $=$ based on $45^{\circ}$ load distribution.

concept sketched in Fig. 2-independent of the specimen width. The experimental results indeed show a threshold value which is then compared to the calculated effective widths based on the studied load spreading methods. The results of this comparison [14] indicate that the effective width should be based on the French load spreading method resulting in $b_{\text {eff }}$ from Fig. 2.

In a next step, a statistical analysis is used to study which load spreading method should be used in combination with EN 1992-1-1:2005 [2]. All experiments on slabs and slab strips under concentrated loads [9] are analysed as well as relevant experiments from literature [15]. The analysis shows that combining $b_{\text {eff } 1}$ and $b_{\text {eff } 2}$ with the shear provisions from EN 1992-1-1:2005 [2] both lead to

In nonlinear finite element models the stress distribution at the support is used to determine the effective width [16]. The requirement for determining the effective width is theoretically that the reaction resulting from the total shear stress over the full support width should equal the maximum shear stress over the effective width. The resulting effective width is shown graphically in Fig. 3 for one of the slab shear experiments (S1T1) In Fig. 3, the effective width from the "experiment" (green line) is based on the experimentally observed inclined cracks on the slab bottom. The results show a good comparison between the effective width resulting from the experimentally observed cracks, the effective width based on the nonlinear finite element calculations and the effective width $b_{\text {eff }}$ according to the French load spreading method (Alternative II in Fig. 3).

Based on the experimental results, the statistical analysis and the nonlinear finite element models, it is proven that the French load spreading method can be used to determine the effective width in shear. This method is now applied to the wheel loads in load model 1 from EN 1991-2:2003 [1] (Fig. 1), for which the effective width is determined per axle. For the axles in the first lane, an asymmetric effective width can be used with the edge distance limiting the effective width at the edge. Using an asymmetric effective width results in the resultant force of the wheel load not coinciding with the resultant force of the distributed shear stress at the support. Additional experiments indicate that an asymmetric effective width for loads near the edge can be used for loads placed with a clear shear span $a_{v}$ (face-to-face distance between the load and the support, Fig. 2) up to $5,4 d_{l}$ ( $d_{l}=$ the effective depth) [17].

A minimum value for the effective width needs to be determined. For the experiment with the load near the edge and $a_{v}=200 \mathrm{~mm}$ it was found that a minimum effective width of $4 d_{l}$ still leads to conservative results in combination with EN 1992-1-1:2005 [2]. The expression for the minimum effective width of $4 d_{l}$ can be used provided that it is the lower bound of $1,3\left(1,5 b_{\text {load }}+d_{l}+b_{r}\right)$ with $b_{\text {load }}$ the width of the load (in the span direction) and $b_{r}$ the distance between the edge and the centre of the load [18]. 


\subsection{Transverse load redistribution and $\beta_{\text {new }}$}

To take into account the higher shear capacities of slabs as compared to beams by virtue of transverse load redistribution, the introduction of an enhancement factor is proposed. This factor can be used to reduce the contribution of concentrated loads to the total shear force [19]. The comparison between experimental results and EN 1992-1-1:2005 [2] with $b_{\text {eff }}$ (Fig. 2) results in a $5 \%$ lower bound for the enhancement factor of at least 1,25. The enhancement factor is valid for loads close to the support. For loads placed at a clear shear span $a_{v}>2,5 d_{l}$ no experimental evidence for the enhancement factor was found.

EN 1992-1-1:2005 [2] prescribes the use of a reduction factor for direct load transfer for the loads close to the support as $\beta=a_{v} / 2 d_{l}$. As the enhancement factor is also applicable in the vicinity of the support, these factors can be combined into $\beta_{\text {new }}=a_{v} / 2,5 d_{l}$ for the case of concentrated loads on slabs with $0,5 d_{l} \leq a_{v} \leq 2,5 d_{l}$.

\subsection{Superposition of loads}

The goal of the second series of experiments under a combination of loads is to verify the hypothesis of superposition. It is found [20] that the shear stresses at the support can be taken as the combination of the shear stress $\tau_{\text {conc }}$ due to the concentrated load distributed over the effective width $b_{\text {eff } 2}$ with the shear stress $\tau_{\text {line }}$ due to the distributed loads over the full slab width, $b$. Thus, the wheel loads from load model 1 can be distributed over the effective width per axle and the resulting shear stress can then be superposed to the shear stress due to the lane load, the superimposed loads and the dead load.

\subsection{Lower bound for shear}

EN 1992-1-1:2005 [2] defines a lower bound for the shear capacity for elements without shear reinforcement at which flexural failure will govern over shear failure. Yielding of the longitudinal reinforcement at a characteristic yield strength $f_{y k}=500 \mathrm{MPa}$ was assumed for the derivation of this lower bound [21]. However, reinforcing bars with a lower yield strength are commonly found in the existing bridges. Before 1962, the standard reinforcement in the Netherlands was of the type "QR24" $\left(f_{y k}=240 \mathrm{MPa}\right)$. To leave out the assumption of $f_{y k}=500 \mathrm{MPa}$, the expression for $v_{\text {min }}$ can be derived as a function of $f_{y k}$ :

$v_{\min }=0,772 k^{3 / 2} f_{c k}^{1 / 2} f_{y k}^{-1 / 2}$

This expression results in a larger value for the lower bound of the shear stress for elements reinforced with lower strength steel, as flexural failure will govern for a larger range of shear stresses.

\section{Improved Quick Scan method}

\subsection{Assumptions with regard to material and geometry}

When possible, the geometric input is taken from the original plans and drawings. The depth of the asphalt layer is typically not known. For the superimposed loads, the asphalt layer can be assumed as $12 \mathrm{~cm}$.

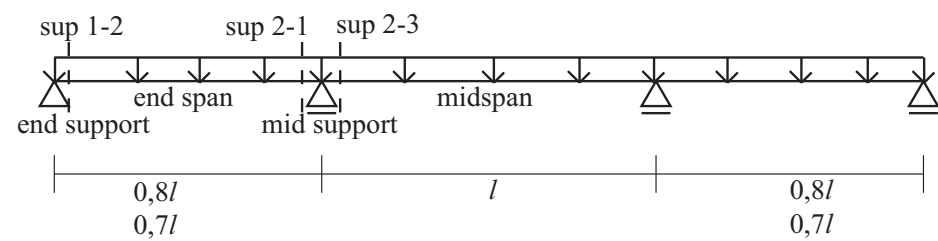

Fig. 4: Considered cross-sections in a typical three-span bridge
The original Quick Scan method is developed for statically determinate structures. To expand the method to statically indeterminate structures, correction factors resulting from a series of case studies [18] are introduced, applicable within the scope of the Quick Scan method. A shear check should be carried out at every cross-section. In the Quick Scan

approach which is discussed here, the cross-sections considered are at the face of the support (see Fig. 4). These locations are governing for shear in solid slab bridges with a constant cross-sectional depth 
The concrete compressive strength of a bridge is substantially larger than the specified compressive strength at 28 days as the result of cement hydration with time. Material research on the existing Dutch highway bridges indicated that, for the slab bridges owned by the Ministry of Infrastructure and the Environment, a minimum concrete cube compressive strength of $45 \mathrm{MPa}$ can be assumed without further verification [22].

\subsection{Live loads}

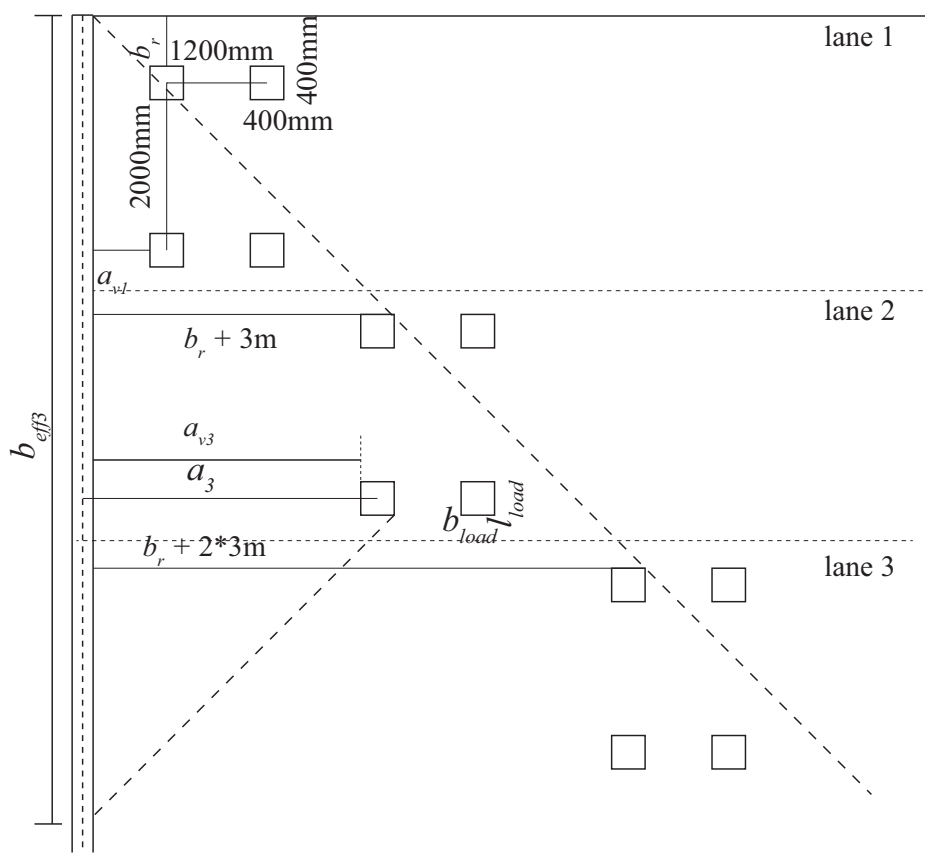

Fig. 5: Most unfavorable position of the design trucks.

Based on the recommendations developed from the experimental research, the most unfavourable position (Fig. 5) of the wheel loads can be determined, resulting in a maximum shear force at the edge of the width. This effect is obtained by placing the first axle in such a way that the faceto-face distance between the support and the tyre $a_{v}$ equals $2,5 d_{l}$. This load configuration is governing since the set of recommendations takes the influence of direct load transfer and transverse load redistribution into account up to $2,5 d_{l}$.In the second and third lane, the design truck is placed in such a way that the effective width associated with the first axle reaches up to the edge of the viaduct. This procedure is illustrated in Fig. 5 for the third axle (first axle of the second design truck). The second design truck is placed in such a way that $b_{\text {eff } 3}$ just reaches the edge of the viaduct.

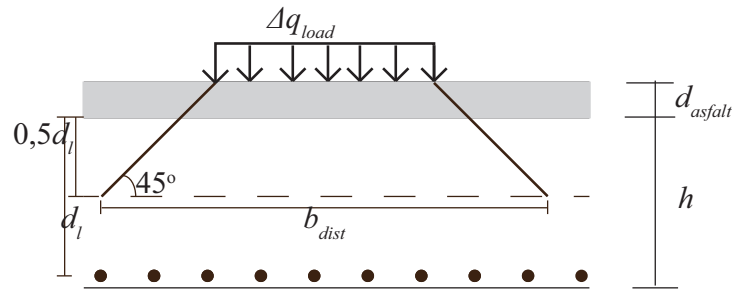

Fig. 6: Determination of the load spreading and contribution for the increased loading on the first lane.
Vertical stress redistribution of the wheel loads $(400 \mathrm{~mm} \times 400 \mathrm{~mm})$ through the $120 \mathrm{~mm}$ asphalt layer is taken at a $45^{\circ}$ angle. The effect of temperature effects on the asphalt layer is not considered, and the structural behaviour is regarded at the concrete surface. Hence, this results in a fictitious wheel print on the concrete surface of $640 \mathrm{~mm} \times 640 \mathrm{~mm}$. In the Quick Scan approach, the tyre contact area as prescribed by EN 1991-2:2003 [1] is replaced by the fictitious tyre contact area on the concrete surface of $640 \mathrm{~mm} \times 640 \mathrm{~mm}$.

Redistribution of forces is also allowed for the additional lane load $\Delta q_{\text {load }}=\left(\alpha_{q 1} \times 9 \mathrm{kN} / \mathrm{m}^{2}-\alpha_{q 2} \times\right.$ $\left.2,5 \mathrm{kN} / \mathrm{m}^{2}\right)$ in the first, heavily-loaded lane. Vertical force redistribution to the mid-depth position of the cross-section $\left(d_{l} / 2\right)$ can be used as shown in Fig. 6.

\section{Case studies}

In an earlier version of the Quick Scan approach, the shear capacity was based on the design shear stress from NEN 6720 [3]. To assess the influence of the implementation of the recommendations combined with determining the shear capacity based on the design shear capacity from EN 1992-1-1:2005[2], case studies have been carried out. In total, 9 existing solid slab bridges having insignificant skew angles, with at least 3 spans and an (almost) constant cross-sectional depth are checked at minimum 3 different cross-sections as shown in Fig. 4. The results are given in Table 1, in which the following columns are given:

$b \quad$ the full width of the viaduct 


$\begin{array}{ll}d_{l} & \text { the effective depth to the longitudinal reinforcement } \\ l_{s p a n} & \text { the length of the span } \\ f_{c k, \text { cube }} & \text { the cube compressive strength of the concrete: based on core measurements or on } \\ & \text { the assumption of a minimum compressive strength of 45MPa when no results are } \\ & \text { available } \\ \text { the percentage of longitudinal reinforcement } \\ \tau_{d} & \text { the design shear stress at the support according to NEN } 6720 \text { (Dutch Code) [3] } \\ & \text { with loads from load model 1 } \\ \tau_{u} & \text { the lower bound design shear capacity according to NEN } 6720 \text { [3] } \\ \text { uc VBC } & \text { the unity check based on NEN } 6720 \text { [3], } \tau_{d} / \tau_{u} \\ v_{E d} & \text { the design shear stress at the support according to EN 1992-1-1:2005 [2], taking } \\ & \text { into account the recommendations based on the experimental research and with } \\ v_{R d, c} & \text { loads from load model 1 } \\ \text { the design shear resistance from EN 1992-1-1:2005 [2] and the recommendations } \\ \text { uc EC } & \begin{array}{l}\text { based on the experimental research } \\ \text { the unity check based on EN 1992-1-1:2005 [2], } v_{E d} / v_{R d, c}\end{array}\end{array}$

Table 1: Results of case studies: cross-sections have been verified based on the Quick Scan with the shear capacity from NEN 6720 [3] and with EN 1992-1-1:2005 [2] and the recommendations.

\begin{tabular}{|c|c|c|c|c|c|c|c|c|c|c|c|}
\hline Section & $\begin{array}{c}b \\
(\mathrm{~m})\end{array}$ & $\begin{array}{c}d_{l} \\
(\mathrm{~m})\end{array}$ & $\begin{array}{l}l_{\text {span }} \\
(\mathrm{m})\end{array}$ & $\begin{array}{l}f_{c k, c u b e} \\
(\mathrm{MPa})\end{array}$ & $\begin{array}{c}\rho \\
(\%) \\
\end{array}$ & $\begin{array}{c}\tau_{d} \\
(\mathrm{MPa})\end{array}$ & $\begin{array}{c}\tau_{u} \\
(\mathrm{MPa})\end{array}$ & uc VBC & $\begin{array}{c}v_{E d} \\
(\mathrm{MPa})\end{array}$ & $\begin{array}{c}v_{R d, c} \\
(\mathrm{MPa})\end{array}$ & uc EC \\
\hline $1 \sup 1-2$ & 9,6 & 0,791 & 9,505 & 45 & 0,443 & 0,35 & 0,66 & 0,52 & 0,27 & 0,45 & 0,60 \\
\hline $1 \sup 2-1$ & 9,6 & 0,791 & 9,505 & 45 & 0,517 & 0,49 & 0,66 & 0,74 & 0,40 & 0,47 & 0,85 \\
\hline 1 sup 2-3 & 9,6 & 0,791 & 13,007 & 45 & 0,517 & 0,52 & 0,66 & 0,78 & 0,45 & 0,47 & 0,95 \\
\hline 1 sup 3-4 & 9,6 & 0,791 & 15,526 & 45 & 0,583 & 0,58 & 0,66 & 0,88 & 0,52 & 0,49 & \\
\hline $2 \sup 1-1$ & 14,45 & 0,331 & 7,04 & 45 & 1,045 & 0,70 & 0,66 & & 0,53 & 0,72 & 0,75 \\
\hline $2 \sup 2-1$ & 14,45 & 0,331 & 7,04 & 45 & 1,045 & 0,92 & 0,66 & & 0,72 & 0,72 & 1,00 \\
\hline $2 \sup 2-3$ & 14,45 & 0,331 & 8,38 & 45 & 1,045 & 0,90 & 0,66 & & 0,73 & 0,72 & \\
\hline 3 sup 1-1 & 11,92 & 0,600 & 7,075 & 58,3 & 0,429 & 0,39 & 0,79 & 0,49 & 0,28 & 0,53 & 0,52 \\
\hline 3 sup 2-1 & 11,92 & 0,600 & 7,075 & 58,3 & 0,429 & 0,52 & 0,79 & 0,66 & 0,40 & 0,53 & 0,75 \\
\hline 3 sup 2-3 & 11,92 & 0,600 & 8,382 & 58,3 & 0,429 & 0,51 & 0,79 & 0,64 & 0,40 & 0,53 & 0,76 \\
\hline 4 sup 1-1 & 11,92 & 0,360 & 7,075 & 70,6 & 0,716 & 0,63 & 0,92 & 0,69 & 0,45 & 0,73 & 0,63 \\
\hline 4 sup 2-1 & 11,92 & 0,360 & 7,075 & 70,6 & 0,716 & 0,83 & 0,92 & 0,91 & 0,62 & 0,73 & 0,85 \\
\hline $4 \sup 2-3$ & 11,92 & 0,360 & 8,382 & 70,6 & 0,716 & 0,81 & 0,92 & 0,88 & 0,63 & 0,73 & 0,87 \\
\hline 5 sup $1-2$ & 13,6 & 0,542 & 9,5 & 48,4 & 0,817 & 0,53 & 0,69 & 0,77 & 0,44 & 0,62 & 0,72 \\
\hline 5 sup 2-1 & 13,6 & 0,542 & 9,5 & 48,4 & 0,909 & 0,72 & 0,69 & & 0,63 & 0,62 & \\
\hline 5 sup 2-3 & 13,6 & 0,542 & 12,50 & 48,4 & 0,909 & 0,73 & 0,69 & & 0,64 & 0,62 & \\
\hline 6 sup $1-2$ & 19,2 & 0,457 & 10 & 49,6 & 0,934 & 0,63 & 0,71 & 0,89 & 0,53 & 0,67 & 0,78 \\
\hline $6 \sup 2-1$ & 19,2 & 0,457 & 10 & 49,6 & 0,934 & 0,84 & 0,71 & & 0,72 & 0,67 & \\
\hline 6 sup 2-3 & 19,2 & 0,457 & 13 & 49,6 & 0,934 & 0,87 & 0,71 & & 0,74 & 0,67 & \\
\hline 7 sup $1-2$ & 14,75 & 0,54 & 9,5 & 37,3 & 0,77 & 0,52 & 0,58 & 0,90 & 0,44 & 0,55 & 0,79 \\
\hline 7 sup 2-1 & 14,75 & 0,54 & 9,5 & 37,3 & 1,284 & 0,71 & 0,58 & & 0,61 & 0,66 & 0,92 \\
\hline 7 sup 2-3 & 14,75 & 0,54 & 14 & 37,3 & 1,284 & 0,77 & 0,58 & & 0,68 & 0,66 & 1,04 \\
\hline 8 sup $1-2$ & 13,36 & 0,59 & 12 & 66,4 & 1,366 & 0,53 & 0,87 & 0,60 & 0,44 & 0,80 & 0,55 \\
\hline 8 sup $2-1$ & 13,36 & 0,59 & 12 & 66,4 & 1,573 & 0,73 & 0,87 & 0,84 & 0,64 & 0,84 & 0,76 \\
\hline 8 sup 2-3 & 13,36 & 0,59 & 15,05 & 66,4 & 1,573 & 0,73 & 0,87 & 0,84 & 0,64 & 0,84 & 0,76 \\
\hline 9 sup $1-2$ & 12,5 & 0,65 & 10 & 74,6 & 0,55 & 0,45 & 0,96 & 0,47 & 0,37 & 0,77 & 0,48 \\
\hline 9 sup 2-1 & 12,5 & 0,65 & 10 & 74,6 & 1,092 & 0,63 & 0,96 & 0,66 & 0,54 & 0,77 & 0,70 \\
\hline $9 \sup 2-3$ & 12,5 & 0,65 & 15 & 74,6 & 1,092 & 0,69 & 0,96 & 0,72 & 0,61 & 0,77 & 0,79 \\
\hline
\end{tabular}

The columns with $\tau_{d}$ and $v_{E d}$ can be compared to determine the influence of the recommendations on the resulting design shear stress. In all cases, the recommendations have resulted in a decrease in the shear stress. This observation can be explained through the contribution of the wheel loads, as the first axle is placed at 2,5d for $v_{E d}$ while for $\tau_{d}$ the first axle is placed at $d_{l}$. As a result, the associated effective width is larger for $v_{E d}$. Moreover, for $v_{E d}$ the load spreading method from the far side of the loading plate can be used, as it is shown that this method is to be preferred in 
combination with EN 1992-1-1:2005 [2], also resulting in a larger effective width.

The columns with $\tau_{u}$ and $v_{R d, c}$ can be used to compare the resulting shear capacities from NEN 6720 [3] and from EN 1992-1-1:2005 [2]. Here, it is confirmed that the recently implemented Eurocode is more conservative for shear. While the shear capacity according to NEN 6720 [3] is based on the concrete compressive strength, the shear capacity from EN 1992-1-1:2005 [2] is based on several factors. As a result, cross-sections with a low percentage of reinforcement have a small shear capacity. Likewise, due to the size effect in EN 1992-1-1:2005 [2], thick cross-sections are observed to have a smaller shear capacity. The influence of the minimum value for the shear capacity as given in Eq. (1) is marked in the column with $v_{R d, c}$ in blue when the lower bound is governing. The lower bound becomes governing when steel QR 24 is used.

The result of the implementation of the recommendations can be seen in the unity checks. Although the provisions for the shear capacity from EN 1992-1-1:2005 [2] are more conservative than those from NEN 6720 [3], the number of cross-sections which do not meet the unity check criterion is reduced from 9 with NEN 6720 [3] to 7 with EN 1992-1-1:2005 [2]. For limited use or current use, an overrun of the unity check with $10 \%$ can be allowed. When the unity check is allowed to be exceeded by $10 \%$ (marked in dark red in Table 1) before more detailed calculations are required, only 1 section remains with the EN 1992-1-1:2005 [2] and recommendations while according to NEN 6720 [3], 6 sections require a more detailed analysis. The recommendations have thus resulted in an improvement of the assessment practice.

\section{Summary and Conclusions}

In the Quick Scan method as developed by the Dutch Ministry of Infrastructure and the Environment, shear assessment is carried out with load factors corresponding to the repair level. A new version of the Quick Scan method based on the recently implemented Eurocodes also takes into account the results of experimental research. The experiments have resulted in the following recommendations:

- Use the effective width resulting from load spreading under $45^{\circ}$ from the far side of the loading plate to the face of the support.

- Use a minimum effective width of $4 d_{l}$.

- For concentrated loads close to the support on slabs, the reduction factor from EN 1992-1$1: 2005 \beta$ can be replaced by $\beta_{\text {new }}=a_{v} / 2,5 d_{l}$.

- The concentrated loads are distributed over their corresponding effective width and the distributed loads over the full width.

- The minimum shear capacity is expressed as a function of $f_{y k}$.

These recommendations are applied to the Quick Scan method and determine the most unfavourable position of the wheel loads. Vertical load spreading through the asphalt layer is accounted for.

A series of case studies on existing solid slab bridges shows the influence of the recommendations resulting in a decreased shear stress at the support.

\section{Acknowledgements}

The authors wish to express their gratitude and sincere appreciation to the Dutch Ministry of Infrastructure and the Environment (Rijkswaterstaat) for financing this research work.

\section{References}

[1] CEN, Eurocode 1 - Actions on Structures - Part 2: Traffic loads on bridges, EN 1991-2. Comité Européen de Normalisation, Brussels, 2002, p. 168

[2] CEN, Eurocode 2-Design of Concrete Structures: Part 1-1 General Rules and Rules for Buildings, EN 1992-1-1. Comité Européen de Normalisation, Brussels, 2005, p. 229.

[3] NORMCOMISSIE 351001, NEN 6720 Technische Grondslagen voor Bouwvoorschriften, Voorschriften Beton TGB 1990 - Constructieve Eisen en Rekenmethoden (VBC 1995), Civieltechnisch centrum uitvoering research en regelgeving, Nederlands Normalisatieinstituut, Delft, 1995, p. 245. 
[4] WALRAVEN, J.C. "Residual shear bearing capacity of existing bridges." fib Bulletin 57, Shear and punching shear in RC and FRC elements; Proceedings of a workshop held on 1516 October 2010 in Salò, Lake Garda, Italy, 2010, pp. 129-138.

[5] HIGGINS, C., DANIELS, T. K., ROSOWSKY, D. V., MILLER, T. H., YIM, S. C., "Assessment and risk ranking of conventionally reinforced concrete bridges for shear." Transportation Research Record: Journal of the Transportation Research Board, Vol. 1928, 2005, pp. 110-117.

[6] AZIZINAMINI, A., BOOTHBY, T. E., SHEKAR, Y., and BARNHILL, G. "Old Concrete Slab Bridges - 1. Experimental Investigation." ASCE Journal of Structural Engineering, Vol. 120, No. 11, 1994, pp. 3284-3304.

[7] COPE, R. J. "Flexural shear failure of reinforced concrete slab bridges." Proceedings of the Institution of Civil Engineers Part 2-Research and Theory, Vol. 79, SEP, 1985, pp. 559-583.

[8] REINECK, K. H., KUCHMA, D. A., KIM, K. S., and MARX, S., "Shear database for reinforced concrete members without shear reinforcement." ACI Structural Journal, Vol. 100, No. 2, 2003, pp. 240-249.

[9] LANTSOGHT, E. O. L., VAN DER VEEN, C., and WALRAVEN, J. C., "Shear capacity of slabs and slab strips loaded close to the support." ACI SP-287, Recent Development in Reinforced Concrete Slab Analysis, Design and Serviceability, 2012, pp. 5.1-5.18.

[10] NORMCOMMISSIE 351001, Beoordeling van de constructieve veiligheid van een bestaand bouwwerk bij verbouw en afkeuren - Grondslagen, NEN 8700, Civieltechnisch centrum uitvoering research en regelgeving, Delft, 2011, p. 56.

[11] NORMCOMMISSIE 351001, Beoordeling van de constructieve veiligheid van een bestaand bouwwerk bij verbouw en afkeuren - Belastingen, NEN 8701, Civieltechnisch centrum uitvoering research en regelgeving, Delft, 2011, p. 26.

[12] STEENBERGEN, R., VROUWENVELDER, T., and SCHOLTEN, N. "Veiligheidsfilosofie bestaande bouw." Cement, Vol. 64, No. 4, 2012, pp. 8-16.

[13] CEN, Eurocode - Basis of structural design, EN 1990. Comité Européen de Normalisation, Brussels, 2002, p. 103.

[14] LANTSOGHT, E.O.L. "Shear tests of reinforced concrete slabs and slab strips under concentrated loads." Proceedings of the 9th fib International PhD Symposium in Civil Engineering, Karlsruhe, Germany, 2012, pp. 3-8.

[15] LANTSOGHT, E.O.L., Shear in reinforced concrete slabs under concentrated loads close to the support-Literature review, Delft University of Technology, 2012, p. 265.

[16] FALBR, J. Shear redistribution in solid concrete slabs. MSc Thesis, Delft University of Technology, 2011, p. 151.

[17] LANTSOGHT, E.O.L., Voortgangsrapportage: Experimenten op platen in gewapend beton onder combinatiebelasting: Deel II: analyse van de resultaten, Delft University of Technology, 2012, p. 98.

[18] LANTSOGHT, E.O.L., VAN DER VEEN, C., GIJSBERS, F.B.J., Achtergrondrapport bij spreadsheet, Delft University of Technology, 2012, p. 50.

[19] LANTSOGHT, E.O.L, Voortgangsrapportage: Experimenten op platen in gewapend beton: Deel II: analyse van de resultaten, Delft University of Technology, 2012, p. 289.

[20] LANTSOGHT, E.O.L., VAN DER VEEN, C., and WALRAVEN, J. " Shear capacity of reinforced concrete solid slabs subjected to a combination of loads" IABSE 2013, Rotterdam, 2013.

[21] WALRAVEN, J. C., Background document for EC-2, Chapter 6.2 Shear. Delft University of Technology, 2002, p. 30.

[22] VERVUURT, A., COURAGE, W., and STEENBERGEN, R. "Betonsterkte bestaande constructies." Cement, Vol. 64, No. 4, 2012, pp. 36-39. 